\title{
Primary care research: does it defy definition?
}

\section{Introduction}

The positive influence of a country's primary care system on the health of its people has been repeatedly demonstrated (Starfield and Shi, 2002; Macinko et al., 2003; Starfield et al., 2005; Beasley et al., 2007), though mostly in industrialized countries. Since each country's primary care needs vary based on the country's epidemiology, local research must be done in order to design, implement, and evaluate primary care in each country. Wealthier countries have health care delivery systems designed to address their epidemiological needs: primarily non-communicable chronic diseases, necessitating continuous coordinated outpatient care. Developing countries likewise have health care delivery systems to address their epidemiological needs, which until recently have been primarily acute infectious diseases, necessitating traditional public health activities and acute treatment. Though non-communicable diseases are increasing, acute infectious diseases remain prominent.

\section{Primary care versus primary health care}

However, there is no simple, commonly agreed definition of 'primary care research' in the literature, making it difficult to evaluate its effect or compare research patterns in different places. This is largely because of the inconsistent use of the terms 'primary care' and 'primary health care' in the literature. Bryar pointed out the problem in the first Editorial of this journal in 2000.

While the terms have often been used interchangeably, 'primary care' refers more to a level of service, the way Barbara Starfield uses the term (Macinko et al., 2003), and 'primary health care' refers more to an approach, as in the Declaration of Alma-Ata (Bryar, 2000).

However, Muldoon et al. (2006), writing from a Canadian perspective, say 'In high-income and middle-income countries, primary health care is mainly understood to be the first level of care. In low-income countries where significant challenges in access to health care persist, it [primary health care] is seen more as a system-wide strategy.' (c) Cambridge University Press 2017
They conclude: "the term "primary care" is more widely used in the literature of developed countries than "primary health care", which is favoured in developing countries' (Muldoon et al., 2006: 409). They are pointing out not just different definitions, but different terminologies commonly used in developed versus developing countries.

Awofeso (2004: 93), a Nigerian working in Australia, illustrates the problem: In developed countries like Australia, he notes that 'primary healthcare is structured as coterminous with population health,' whereas 'primary care... is concerned with "family doctor-type" services.' But these distinct shades of meaning are not universally accepted. In response, Awofeso proposes that clinical primary care be seen as distinct from public health, whereas the term primary health care should involve both clinical care and public health (Awofeso, 2004). Van Weel et al. propose a similar distinction, calling primary care 'personal care', and primary health care 'community-oriented primary care' (2008).

However, Awofeso admits that the problem has not been resolved, quoting the World Health Report of 2003 that 'no uniform, universally acceptable definition of primary health care exists'. The same Awofeso adds, 'can be said for "primary care"' (Awofeso, 2004: 94).

\section{Primary care research}

How, then, can we define primary care research? Starfield writes, 'In my view, the only meaningful definition of primary care research is research done in a primary care context' (1996: 181). Van Weel (2007) writes extensively about primary care research, or even 'research in primary care,' echoing Starfield's definition, but stops short of calling this a definition. Understandably: without commonly agreed definitions of primary care and primary health care, Starfield's definition of primary care research is not helpful for comparing research done in other settings.

Despite these difficulties, there has developed over the last decade a consensus (at least among scholars from developed countries) regarding a classification of primary care research. 
Table 1 Showing Masters of Medicine Research at Moi University, 2005-2015

\begin{tabular}{llll}
\hline Department & $\begin{array}{l}\text { Total } \\
\text { theses }\end{array}$ & $\begin{array}{l}\text { Primary care - } \\
\text { Starfield } \\
\text { definition }\end{array}$ & $\begin{array}{l}\text { Primary care - } \\
\text { Relevance } \\
\text { definition }\end{array}$ \\
\hline Family Medicine & 28 & 15 & 27 \\
Internal Medicine & 14 & 0 & 7 \\
Pediatrics & 13 & 3 & 5 \\
Totals & 55 & 18 & 39 \\
\hline
\end{tabular}

Mash (2014: 2) [drawing from Beasley et al. (2007)], writing specifically for an African context, summarizes five categories:

- Basic: 'studies that "help develop the research tools for primary care".'

- Clinical: "focuses on the burden of disease and the clinical processes involved.'

- Health Services: 'focuses on the way primary care is organized and the processes involved.'

- Health Systems: 'is more at a policy level and may look at the relationship of health policies to other political, social or economic systems.'

- Educational: 'focuses on the development of educational programs for family medicine and primary care and continuing professional development.'

He then suggested some examples of further categories under clinical and health services.

For example, for clinical: the natural history, epidemiology, diagnosis, and management of common problems; improving quality of care; implementing guidelines; qualitative assessment of the patient's care experience. For health services: access to primary care services, assessment of continuity, coordination, and comprehensiveness of care.

This classification may give a Masters student interested in primary care research some direction in choosing an approach or topic. However, it cannot be used to evaluate or compare research already done, because we have no commonly agreed means of determining which research can be classified as primary care research.

\section{Examples}

At Moi University we endeavored to do an audit of all Masters research done in the first three departments offering the Master of Medicine
(MMed): Family Medicine, Pediatrics, and Internal Medicine, each of which could be expected to contribute to primary care. All began in 2005; thus each has had 10 years of research experience. Our aim was to compare the primary care research interests of the three departments.

We found 55 successfully defended theses from these three departments by the end of 2015 (see Table 1). We attempted to classify them as primary care or not, based on where the research was done. Most of the Medicine and Pediatric research was carried out at the Teaching and Referral Hospital of the School of Medicine, and was therefore by Starfield's definition not primary care. On the other hand, most of the Family Medicine research was carried out in the hospitals where the Family Medicine training was located: two mission hospitals and two district-level hospitals.

Following Mash's addendum to the Starfield definition of primary care research ['In the African context, one might also speak of research conducted in the health district as family physicians may also work as generalists in the district hospital' (Mash, 2014: 2)], we classified the district hospital studies as being carried out in primary care settings. However, the mission hospitals were both quite large and offered many services comparable to, or beyond, those in the Teaching and Referral hospital. Therefore we could not classify these studies as primary care. In summary, only 18 of the 55 theses could be called primary care research. However, if we used a more subjective definition of primary care research, that is research of relevance to those working in primary care, we found 39 of the 55 to be primary care (see Table 1 ).

To determine relevance, we considered research addressing conditions commonly seen and managed by primary care providers in their setting. A few specific examples will illustrate the problem. One of the Internal Medicine theses sought to validate the Wells clinical criteria for diagnosing deep vein thrombosis - especially relevant for primary care providers, as they may need to refer the patient for more definitive treatment. However, since the study was carried out at the teaching and referral hospital, it would not be considered primary care research according to the Starfield definition. A Pediatric study of suspected pyogenic meningitis patients in the referral hospital described their presenting symptoms, organisms, and antibiotic sensitivities. Primary care providers who 
treat meningitis in district hospitals could use these findings to guide appropriate empiric antibiotic therapy, as cultures and sensitivities are not usually available in district hospitals. However, the location of the study excludes it as primary care research according to the Starfield definition.

Finally, a Family Medicine study sought to determine the significance of malarial retinal findings in children with coma.

Since the study was performed in the district hospital, it would be considered primary care according to the Starfield/Mash definition. However, the relevance of this study is totally dependent on the context of the primary care clinicians. In a place where there is no malaria, malaria is certainly not a primary care issue, and the study is irrelevant. Likewise in a malarious place where primary care workers do not use ophthalmoscopes, the study has no relevance. However, knowing the retinal findings of malaria in a child with coma of uncertain cause in a malarious area would be quite relevant for primary care clinicians with ophthalmoscopes.

\section{The problems}

The first problem we identified, then, was the definition of primary care research. In order to classify and compare primary care research, we would need a definition that is applicable in all contexts. Since, as we have shown, primary care is understood differently in developed and developing countries, creating such a definition would be very difficult. Considering primary care research as that research which is relevant to primary care providers in that same context is the starting point that we suggest.

Another problem we found was in the classification. We did find the general classification by Beasley et al., modified by Mash, to be a good beginning. However, when trying to classify the topics we were reviewing, we needed to modify the classification. While most authors writing on this topic admit that the categories proposed are overlapping (Mold and Green, 2000; Beasley et al., 2007), we found no clear categories for areas commonly researched such as health-seeking behavior, screening, and other prevention activities.

It also seemed that none of the published categories gave sufficient attention to the patients' experience of the disease, though Mash did mention this under clinical research.
Finally, in our audit almost all of the studies carried out by MMed students addressed either clinical or health service questions. This is perhaps understandable for Masters level research, as basic research into the tools of primary care research is more likely to require much larger databases and to be at a higher level. The same is true for health systems research. Moreover, basic and health systems research, while vital to the overall understanding or primary care, may be of limited interest to primary care clinicians.

\section{Conclusion}

The terms 'primary care' and 'primary health care' carry different shades of meaning in different parts of the world. The lack of a simple commonly agreed definition of primary care research and/or primary health care research coupled with the inconsistent use of the terms primary care and primary health care, makes it difficult to compare primary (health) care research done in different locations. Yet the importance of primary care for a nation's health makes it imperative that primary care research findings be shared internationally. This sharing will be far more relevant using commonly shared definitions of primary care research. We suggest that primary care research is that research which is relevant to primary care analysts and providers. We would also suggest a further modification of the classification of primary care research to include patient's health-seeking behavior, screening and other prevention activities, and patient's experience of the disease.

$$
\begin{array}{r}
\text { James Amisi } \\
\text { School of Medicine, Moi University } \\
\text { Nandi Road, Kenya } \\
\text { Email: jamesakiruga@gmail.com } \\
\text { Raymond Downing } \\
\text { School of Medicine, Moi University } \\
\text { Nandi Road, Kenya }
\end{array}
$$

\section{Acknowledgments}

The authors acknowledge Moi University specifically the principal of the College of Health Sciences 
and the dean of the School of Medicine for granting us unrestricted access to the theses of students in the various departments under their jurisdiction.

\section{Conflicts of Interest}

None.

\section{Ethical Approval}

The authors obtained approval to carry out the theses audit from Moi University's Research and Ethics Committee.

\section{References}

Awofeso, N. 2004: What is the difference between 'primary care' and 'primary healthcare'? Quality in Primary Care 12, 93-94.

Beasley, J., Starfield, B., van Weel, C., Rosser, W. and Haq, C. 2007: Global health and primary care research. Journal of the American Board of Family Medicine 20, 518-26.

Bryar, R. 2000: Primary health care: does it defy definition? Primary Health Care Research and Development 1, 1-2.
Macinko, J., Starfield, B. and Shi, L. 2003: The contribution of primary care systems to health outcomes within Organization for Economic Cooperation and Development (OECD) countries, 1970-1998. HSR: Health Services Research 38, 831-65.

Mash, B. 2014: African primary care research: choosing a topic and developing a proposal. African Journal of Primary Health Care \& Family Medicine 6, 1-6.

Mold, J. and Green, L. 2000: Primary care research: revisiting its definition and rationale. Journal of Family Practice 49, 206-8.

Muldoon, L., Hogg, W. and Levitt, M. 2006: Primary care (PC) and primary health care (PHC): what is the difference? Canadian Journal of Public Health 97, 409-11.

Starfield, B. 1996: A framework for primary care research. Journal of Family Practice 42, 181-85.

Starfield, B. and Shi, L. 2002: Policy relevant determinants of health: an international perspective. Health Policy 60, 201-18.

Starfield, B., Shi, L. and Macinko, J. 2005: Contribution of primary care to health systems and health. The Milbank Quarterly 83, 457-502.

Van Weel, C. 2007: Research in primary care: how to live up to its needs? Primary Health Care Research and Development $8,1-2$.

Van Weel, C., De Maeseneer, J. and Roberts, R. 2008: Integration of personal and community health care. The Lancet 372, 871-72. 